\title{
Correction to: The 2018 new definition of periprosthetic joint infection improves the diagnostic efficiency in the Chinese population
}

Haitao Guan ${ }^{1,3+}$, Jun $\mathrm{Fu}^{1+}$, Xiang $\mathrm{Li}^{1^{*}}$, Wei Chai ${ }^{1}$, Libo Hao ${ }^{1}$, Rui Li ${ }^{1}$, Jing Zhao ${ }^{2}$ and Jiying Chen ${ }^{1 *}$

\section{Correction to: J Orthopaedic Surg Res http://dx.doi.org/10.1186/s13018-019-1185-y}

In the original publication of this article, [1] the affiliation of the first author Haitao Guan needs to be revised:

Haitao Guan ${ }^{1,3+}$.

${ }^{1}$ Department of Orthopaedics, Chinese People's Liberation Army General Hospital (301 Hospital), Beijing, People's Republic of China.

${ }^{3}$ School of Medicine, Nankai University, Tianjin 300, 071, People's Republic of China.

\footnotetext{
Author details

'Department of Orthopaedics, Chinese People's Liberation Army General Hospital (301 Hospital), Beijing, People's Republic of China. ${ }^{2}$ Anesthesia/ Surgery Center, Chinese People's Liberation Army General Hospital (301 Hospital), Beijing, People's Republic of China. ${ }^{3}$ School of Medicine, Nankai University, Tianjin 300071, People's Republic of China.
}

Published online: 28 October 2019

\section{Reference}

1. Guan, et al. The 2018 new definition of periprosthetic joint infection improves the diagnostic efficiency in the Chinese population. J Orthop Surg Res. 2019;14:15. https://doi.org/10.1186/s13018-019-1185-y.

\footnotetext{
*Correspondence: stevelee301@163.com; jiyingchen_301@163.com ${ }^{+}$Haitao Guan and Jun Fu are co-first authors.

'Department of Orthopaedics, Chinese People's Liberation Army General Hospital (301 Hospital), Beijing, People's Republic of China

Full list of author information is available at the end of the article
}

(c) The Author(s). 2019 Open Access This article is distributed under the terms of the Creative Commons Attribution 4.0 International License (http://creativecommons.org/licenses/by/4.0/), which permits unrestricted use, distribution, and reproduction in any medium, provided you give appropriate credit to the original author(s) and the source, provide a link to the Creative Commons license, and indicate if changes were made. The Creative Commons Public Domain Dedication waiver (http://creativecommons.org/publicdomain/zero/1.0/) applies to the data made available in this article, unless otherwise stated. 